\title{
Disentangling encoding versus retrieval explanations of the bizarreness effect: Implications for distinctiveness
}

\author{
MARK A. MCDANIEL and COURTNEY C. DORNBURG \\ University of New Mexico, Albuquerque, New Mexico \\ and \\ MELISSA J. GUYNN \\ New Mexico State University, Las Cruces, New Mexico
}

\begin{abstract}
Recall effects attributed to distinctiveness have been explained by both encoding and retrieval accounts. Resolution of this theoretical controversy has been clouded because the typical methodology confounds the encoding and retrieval contexts. Using bizarre and common sentences as materials, we introduce a paradigm that decouples the nature of the encoding context (mixed vs. unmixed lists of items) from the retrieval set (mixed vs. unmixed retrieval sets). Experiment 1 presented unmixed lists for study, and Experiment 2 presented mixed lists for study. In both experiments, significant bizarreness effects were obtained in free recall when the retrieval set intermixed items but not when the retrieval set consisted of only one item type. Also, Experiment 1, using a repeated testing procedure, did not reveal evidence for more extensive encoding of bizarre sentences than of common sentences. The results support the idea that retrieval dynamics primarily mediate the bizarreness effect, and perhaps more generally, distinctiveness effects.
\end{abstract}

One of the most persistent and galvanizing issues in memory research and theory has been the relative contributions of encoding versus retrieval processes to retention. The issue is sharply drawn in the debate concerning the locus of distinctiveness effects in memory. A commonly accepted claim, both as an empirical description and sometimes as an explanatory construct for empirical findings (Hunt \& Lamb, 2001; Schmidt, 1991), is that distinctiveness enhances memory. There is far less agreement, however, about whether encoding processes or retrieval processes are responsible for so-called distinctiveness effects. Certainly, part of the debate turns on the complexity of the issue and the possible contribution of either encoding or retrieval processes across variations in materials, procedures, participants, and so on (see Schmidt, 1991, for a review). We suggest though that part of the persistence of this theoretical debate hinges on a problematic aspect of the research methodology that

We thank Kristen Hayes and Scot Jones for assistance with Experiment 2, Jennifer Breneiser for helping with data scoring in Experiment 2, and Gordon Brown, Cathy McEvoy, and Bruce Whittlesea for helpful comments regarding this article. Experiment 2 was presented in part at the April 2001 meeting of the Rocky Mountain Psychological Association in Reno, Nevada. Portions of these experiments were also presented at the Annual Meeting of the Psychonomic Society in Kansas City, MO, November 2002, and a partial set of results from a subset of participants was reported in a book chapter (McDaniel \& Geraci, in press). Correspondence should be addressed to M. A. McDaniel, Department of Psychology, Washington University, One Brookings Drive, St. Louis, MO 63130 (e-mail: mmcdanie@artsci.wustl.edu). characterizes the work often related to distinctiveness. In this article, we first summarize the theoretical debate and identify the methodological problem. We then report two experiments designed to remedy the methodological problem, with the goal of disentangling encoding influences from retrieval influences in distinctiveness effects.

We embed the development of our ideas primarily in the context of the effects of bizarre stimulus materials on free recall, an effect that has been closely linked to distinctiveness processes (Einstein \& McDaniel, 1987; McDaniel, DeLosh, \& Merritt, 2000; McDaniel \& Einstein, 1986; McDaniel, Einstein, DeLosh, May, \& Brady, 1995; Waddill \& McDaniel, 1998). In a popular paradigm, bizarre materials are constructed by presenting common items in bizarre relations to one another, either through pictorial or sentential materials (e.g., The MAID licked AMMONIA off the TABLE). Parallel common materials use the same items related in a usual fashion (e.g., The MAID spilled AMMONIA on the TABLE). The standard finding is that when the bizarre and common materials are intermixed in the acquisition list, bizarre items are better recalled than common items. By contrast, when the bizarre and common items are presented in unmixed lists, there is no free recall advantage of bizarre items (see Einstein \& McDaniel, 1987, for a review, and more recently McDaniel et al., 1995). This effect of list composition with regard to distinctiveness-like effects is not limited to materials that are specifically bizarre, but also extends to other presentations that might be associated with distinctive features. For example, fragmented items (that are gener- 
ated) generally show better free recall than intact items (that are read) in mixed but not unmixed lists (Hirshman \& Bjork, 1988; Slamecka \& Katsaiti, 1987), humorous sentences are better recalled than nonhumorous sentences in mixed but not unmixed lists (Schmidt, 1994), and orthographically distinct items are better recalled than orthographically regular items in mixed but not unmixed lists (Hunt \& Elliott, 1980).

\section{Encoding Views of Bizarreness Effects}

From an encoding view, to account for the predominant finding that the bizarreness effect emerges in mixed lists and not unmixed lists, the assumption is that the unusual or distinctive nature of the bizarre stimuli is especially prominent when those stimuli are encountered in an encoding context (mixed list) that highlights and attracts attention to the differences of the stimuli relative to more common material. The idea is further that the distinctiveness of the bizarre stimuli becomes muted when all of the materials in the encoding context are bizarre (unmixed list). Various encoding accounts have followed from this general theme. A seminal, popular view is that differential attention to the unusual items in a list accounts for distinctiveness effects (Jenkins \& Postman, 1948). This idea has been directly applied to bizarre imagery effects: Because mixed lists highlight the unusual nature of the bizarre items, these items are assumed to receive a greater amount of processing (Merry, 1980; Wollen \& Cox, 1981). Even when processing time is nominally equated for the bizarre and common sentences via experimenter-paced presentations of the sentences, the idea is that participants would favor study of bizarre over common items and might even persist in processing the bizarre items during presentation of the common items (e.g., see Slamecka \& Katsaiti, 1987, for explication of this view with regard to generation effects, and Watkins, LeCompte, \& Kim, 2000, for application of this view to superior free recall of rare words relative to common words in mixed lists).

A related approach is that unusual items violate expectations and thereby create more extensive processing of the general context in which the item appears (in an attempt to determine the significance of the weird item; see Hirshman, Whelley, \& Palij, 1989). The greater contextual encoding associated with bizarre items subsequently contributes to better free recall, a test for which retrieval cues are impoverished. Again, the core idea is that during encoding, bizarre items stimulate the encoding of features that are additional to those that are encoded with common items (and maybe especially so in mixed lists; see Worthen, Marshall, \& Cox, 1998), so that bizarre items have an advantage in free recall.

Another view is more specific to the typical paradigm in which bizarre imagery effects are demonstrated. In this paradigm, the orienting task requires participants to form mental images of the verbal stimuli. Wollen and Margres (1987) suggested that bizarre materials require more mental effort for image generation (because the bi- zarre images are not canonical), and it is this increased mental effort toward image generation that produces a more memorable encoding for bizarre items. Presumably, in mixed lists, which produce the positive effects of bizarre imagery on free recall, the effort differential is more pronounced when generation of bizarre images must be completed in the context of also generating common images.

These explanations emphasize the favored processing conferred when unusual material is presented in a context in which that material could be said to appear more "distinctively" (mixed lists). Note that some views go further and use the term distinctiveness as an explanatory construct as well. The idea here is that more elaborative encoding (e.g., enjoyed by unusual material in mixed lists) produces an encoding that is more distinctive and thus more memorable (see Hunt \& McDaniel, 1993; Mulligan, 2000; Waddill \& McDaniel, 1998). For present purposes, however, the critical point is that encoding processes stimulated especially in a mixed-list context (in which unusual material might be said to be distinctive) play a prominent role in producing the bizarreness effect in free recall. For ease of exposition, we will use the term encoding view to refer to these various accounts.

\section{Retrieval Views of Bizarreness Effects}

A dramatically different point of view is that distinctiveness, and the advantage in recall attributed to distinctiveness, is a consequence of retrieval processes. This view emphasizes the notion that item distinctiveness depends on the feature set to which the target features are aligned during retrieval (see Hunt \& McDaniel, 1993). The idea is that if all of the stimuli in a retrieval set ${ }^{1}$ share features, then the features are not functionally distinct and no retrieval advantage is gained (for formal development of this idea see, e.g., Brown, Neath, \& Chater's, 2002, SIMPLE model; see also Nairne, 1990; Neath, 2000). On this view, in unmixed lists only bizarre stimuli are encompassed in the retrieval set specified by the retrieval instructions ("recall the list of sentences that you just studied"). Relative to this retrieval environment, any particular bizarre stimulus is not distinctive, and therefore unmixed lists of bizarre items are not recalled better than unmixed lists of common items (Cox \& Wollen, 1981; Hauck, Walsh, \& Kroll, 1976; Senter \& Hoffman, 1976; Wollen, Weber, \& Lowry, 1972). In mixed-list manipulations, because common stimuli are also included in the list, the bizarre features become functionally distinctive in the context of the retrieval set (see McDaniel \& Einstein, 1986; McDaniel et al., 1995; McDaniel et al., 2000). These bizarre features can then be exploited to help reconstruct or recover items for recall, thereby supporting better recall for bizarre than for common stimuli in mixed lists. On some views, such distinctive features that emerge in the retrieval context confer privileged routes to retrieval (Knoedler, Hellwig, \& Neath, 1999; but see McDaniel et al., 2000). We will label this general approach the retrieval view. 


\section{The Encoding-Retrieval Context Confound}

Despite a growing literature, the encoding and retrieval views of the bizarreness effect have been difficult to legislate and both still enjoy proponents (e.g., see McDaniel et al., 2000, and Worthen et al., 1998). Similarly, disentangling the source of distinctiveness effects as they apply to mixed-list presentations has been a long-standing issue in memory (Hunt, 1995; Hunt \& Lamb, 2001). The intractability of the theoretical problem hinges in part on the experimental methodology, in which the encoding and retrieval contexts are perfectly correlated. Mixed lists are presented for encoding, and recall is tested for the entire list so that the retrieval context recapitulates the encoding context. Similarly, items encoded in an unmixed list are also recalled in the context of the same unmixed list. Thus, it is uncertain whether the reported patterns are a consequence of the encoding set, the retrieval set, or both.

Some current approaches to this conundrum have used mathematical modeling to try to estimate the relative influence of encoding and retrieval in the bizarreness effect (Riefer \& Rouder, 1992). These approaches are limited in that they are indirect. Others have manipulated encoding demands or retrieval strategies (or both) to assess the impact of these processes on the bizarreness effect (e.g., McDaniel et al., 2000; Waddill \& McDaniel, 1998; Worthen, Starns, \& Loveland, in press). For example, Waddill and McDaniel presented materials at a relatively rapid presentation rate to try to preclude differential attention to bizarre versus common sentences and thereby rule out a differential encoding hypothesis for the bizarreness effects that were obtained in mixed lists. In principle, however, differential encoding could be operative even when presentation rates are relatively fast.

On the retrieval side, McDaniel et al. (2000) varied retrieval strategies by affording the use of information other than distinctiveness during recall (e.g., serial order information, category information). The reasoning here is that if differential attention at encoding is mediating the bizarreness effect, then regardless of free recall strategy, a better attended item should generally be better recalled. Alternatively, if retrieval processes are paramount, then use of information other than distinctiveness could eliminate the effect. McDaniel et al. (2000) reported no bizarreness effect when alternative retrieval strategies were encouraged. However, the prominence of alternative information during encoding (serial order information, category information) could have influenced the encoding dynamics such that differential attention to bizarre items was mitigated.

In this study, we adopted a more direct experimental approach to investigate the role of encoding and retrieval factors in bizarreness effects in order to further inform the dynamics of distinctiveness effects in memory. Our approach was to decouple the encoding context from the retrieval context such that unmixed encoding was paired with either unmixed or mixed retrieval sets (Experiment 1), and likewise mixed encoding was paired with either unmixed or mixed retrieval sets (Experiment 2).

\section{EXPERIMENT 1}

In this experiment, participants received one pure list of bizarre sentences and one pure list of common sentences. Retrieval contexts were then manipulated by having one group of participants recall each list separately and another group recall both lists at once. Therefore, some participants recalled pure lists of all bizarre items followed by all common items (or vice versa), while others attempted recall of bizarre and common items concurrently.

As previously noted, pure list presentation of bizarre and common items typically produces no significant free recall advantage of bizarre items (Einstein \& McDaniel, 1987; McDaniel \& Einstein, 1986), even in a paradigm in which pure-list presentation of one kind of sentence is followed by presentation of a pure list of the alternative kind of sentence, as in the present experiment (Einstein, McDaniel, \& Lackey, 1989, Experiment 1; the result rests on a between-subjects comparison of recall of bizarre items when a common list followed versus recall of common items when a bizarre list followed). Therefore, as described above, differential encoding of bizarre and common items might be assumed to obtain only when bizarre and common items are intermixed in the same study list. That is, only when bizarre items are distinctive within the encoding context should bizarre items receive the additional processing or attention presumed to underlie the bizarreness effect (from the perspective of an encoding view). Accordingly, neither pure-list recall nor mixed-list recall should evidence a bizarreness advantage.

The retrieval account of bizarreness effects predicts a different pattern. By this view, the condition that requires recall of both bizarre and common sentences should produce a bizarreness effect, but not the condition that requires the recall of each list in turn. In the combined retrieval condition, bizarre sentences become distinctive by virtue of the presence of common sentences in the retrieval set. In the separate retrieval condition, bizarre sentences no longer enjoy advantaged retrieval because they are not distinctive in the retrieval set.

A second important feature of this experiment was that the combined retrieval group was required to perform recall three successive times. We used the multiple recall procedure to provide converging assessment for the view that bizarre items enjoy more extensive encoding than common items (i.e., an encoding view of distinctiveness effects). Across multiple tests, some items not initially recalled can be recalled on later tests. Studies have consistently demonstrated that these so-called item gains are consistently more robust for items that have been more richly or extensively encoded because of experimenter-provided orienting tasks (Burns, 1993; Klein, Loftus, Kihlstrom, \& Aseron, 1989; McDaniel, Moore, \& Whiteman, 1998; Mulligan, 2000, 2001). One account of these effects is that "an item with many encoded attributes will, if not recalled on an initial trial, nevertheless have a better chance of some critical subset 
of those items being sampled on some subsequent trial than would an item with fewer encoded attributes" (McDaniel et al., 1998, p. 175). Consequently, examination of item gains across multiple tests has been advocated and successfully used as a metric of item elaboration at encoding (Burns, 1993; see also Mulligan, 2001).

For present purposes, the prediction from the encoding view is that any advantage of bizarre items should be accompanied by significantly greater item gains for bizarre than for common items. If this finding were to obtain, it would suggest that bizarre imagery effects are mediated by more extensive encoding of bizarre items. Alternatively, bizarreness effects in the combined retrieval group along with an absence of significantly greater item gains for bizarre versus common items would favor the view that retrieval context, not differential encoding, plays a major role in bizarreness effects (and by extension, perhaps other distinctiveness effects as well). Note that we did not collect multiple-testing data for the separate-retrieval group because it is uncertain whether the item-gain dynamics are clouded when repeated testing of one list is interrupted by testing of another list (see Burns \& Gold, 1999).

\section{Method}

Participants and Design. Participants were 64 University of New Mexico undergraduates who participated either in partial fulfillment of a course requirement or for extra credit. All participants were presented an unmixed bizarre-sentence list and an unmixed common-sentence list so that sentence type was varied within subjects. Retrieval condition was varied between subjects, with participants randomly assigned to one of two retrieval conditions: separate-list recall (common nouns recalled at one time and bizarre nouns at another time) or combined-list recall (common and bizarre nouns recalled together). There were 32 participants in each retrieval condition.

Materials. The materials consisted of capitalized noun triplets embedded in simple sentences. A total of 12 triplets was used, with bizarre and common sentences constructed for each noun triplet by varying the relationship among the nouns (selected from McDaniel \& Einstein's, 1986, Appendix). For example, one common sentence was "The MAID spilled AMMONIA on the TABLE," and the corresponding bizarre sentence was "The MAID licked AMMONIA off the TABLE." Unmixed lists of bizarre and common sentences were constructed so that each list contained six bizarre sentences or six common sentences. Each participant was presented with six of the noun triplets in a bizarre list and the remaining six triplets in a common list. The particular type of list in which noun triplets appeared was counterbalanced across participants, as was the order in which the bizarre and common lists were presented. For purposes of generality, the order of the sentences within the bizarre and common lists was varied by exchanging the first three sentences with the last three sentences, and these different-ordered lists were counterbalanced across participants.

The sentences were presented in booklets, with one sentence per page. The six sentences in the first list were always presented in italicized print on green paper, while the six sentences in the second list were always presented in bold print on purple paper. This was done to provide differentiation between the lists.

Procedure. Participants were asked to read sentences one at a time, creating a mental picture of each sentence's content and including the capitalized nouns. For each sentence, participants rated the vividness of their image on a scale of 1 (not vivid) to 5 (very vivid) on a separate rating scale answer sheet. No mention was made of the number of sentences they would read nor of the subse- quent memory test. After completing two sample common sentences, participants were presented with a list of six sentences, one at a time, for $10 \mathrm{sec}$ each.

Next, participants worked math problems for $5 \mathrm{~min}$. The math problems were intended to create maximal segmentation between the two lists, as well as to purge working memory of local contextual information that might create a set against which subsequent items would be contrasted during encoding (see Schmidt, 1991; Worthen et al., 1998). Participants then imaged the second list of six sentences and worked math problems for $5 \mathrm{~min}$. Half of the separatelist retrieval group was then instructed to recall the target (capitalized) nouns from the first list of six sentences and were given $2.5 \mathrm{~min}$ to write their recalled words on a response sheet. Then, these participants were instructed to recall the target nouns from the second list of sentences on a separate response sheet and were again given $2.5 \mathrm{~min}$ to do so. The other half of the separate-list group first recalled the target nouns from the second list, followed by recall from the first list. In order to help participants segment the lists, the experimenter reminded them that the first list of sentences had been presented on green pages and the last list of sentences had been presented on purple pages. Combined-list retrieval participants were given $5 \mathrm{~min}$ to recall the target nouns from all 12 sentences on a single response sheet. Following the initial recall, participants in the combined-list group were asked to repeat this procedure two additional times (again for $5 \mathrm{~min}$ each). The rationalization presented to participants for the follow-up memory tests was that "some people find they are able to recall words in later attempts that they forgot the first time."

\section{Results}

Free recall. We first contrasted performance on the initial recall test for the combined-retrieval group with the recall performance for the separate-retrieval group. The magnitude of the bizarreness effects was determined by eta squared $\left(\eta^{2}\right)$. Table 1 presents the mean proportion of target nouns recalled as a function of retrieval group and sentence type (bizarre, common). ${ }^{2}$ These data were first submitted to a $2 \times 2$ mixed analysis of variance (ANOVA), with sentence type as the within-subjects factor and retrieval group as the between-subjects factor (the ANOVA was conducted on number of nouns recalled). Planned comparisons were also conducted to test the predictions regarding the bizarreness effect for each retrieval group. The ANOVA indicated that nouns from bizarre sentences were recalled better than nouns from common sentences $\left[F(1,62)=14.83, M S_{\mathrm{e}}=8.77, p<\right.$ $\left..0005, \eta^{2}=.19\right]$. There was no significant effect of retrieval group $(F<1)$, nor was the interaction between retrieval group and sentence type significant $[F(1,62)=$ $\left.2.50, p<.12, \eta^{2}=.04\right]$. The planned contrasts indicated that the recall advantage for bizarre relative to common sentences was statistically significant when retrieval of

\section{Table 1}

Experiment 1: Mean Free Recall and Standard Error as a Function of Sentence Type and Retrieval Condition

\begin{tabular}{clllll}
\hline & \multicolumn{2}{c}{ Bizarre } & & \multicolumn{2}{c}{ Common } \\
\cline { 2 - 3 } \cline { 5 - 6 } Retrieval Condition & $M$ & $S E$ & & $M$ & $S E$ \\
\hline Combined recall & .47 & .03 & & .31 & .04 \\
Separate recall & .38 & .03 & & .31 & .04 \\
\hline
\end{tabular}

Note-Combined recall attempted recall of both lists together; separate recall attempted recall of each list successively. 
bizarre and common lists was combined $[F(1,62)=14.75$, $\left.M S_{\mathrm{e}}=8.77, p<.0005, \eta^{2}=.19\right]$. However, there was no significant bizarreness advantage when bizarre and common items were recalled as separate lists $[F(1,62)=$ $\left.2.57, p>.10, \eta^{2}=.04\right]$.

Gains and losses. Repeated test scores for the combined retrieval condition are shown in Table 2, along with the gain scores (items recalled on test $N$ that were not recalled on test $N-1$ ) and loss scores (items not recalled on test $N$ that were recalled on test $N-1$ ). A $3 \times$ 2 within-subjects ANOVA (with test number and material type as factors) on recall scores showed that recall levels increased significantly across successive tests (i.e., hypermnesia) $\left[F(2,62)=18.72, M S_{\mathrm{e}}=1.30, p<\right.$ $\left..0005, \eta^{2}=.38\right]$. There was no interaction between sentence type and test number $(F<1)$, as both bizarre and common items showed similar increases in recall (1.09 and 1.35 average item increases across tests for bizarre and common items, respectively). As in the analysis on the initial test, the three successive tests continued to show a significant bizarreness advantage $[F(1,31)=$ $\left.11.78, M S_{\mathrm{e}}=26.74, p<.005, \eta^{2}=.28\right]$.

More important, as shown in Table 2, the gains in items recalled across tests (i.e., reminiscence) did not reveal any consistent advantage for bizarre items. A $2 \times 2$ within-subjects ANOVA confirmed there was no effect of sentence type on gains $(F<1)$. Sentence type interacted with test number $\left[F(1,31)=5.80, M S_{\mathrm{e}}=0.91, p<\right.$ $\left..05, \eta^{2}=.16\right]$; common items showed more gains than bizarre items from Test 1 to Test $2[F(1,31)=6.20, p<$ $.05]$ but not from Test 2 to Test $3(F<1)$. Finally, there were more gains from Test 1 to Test 2 than from Test 2 to Test $3\left[F(1,31)=6.44, M S_{\mathrm{e}}=0.91, p<.05, \eta^{2}=.17\right]$. For losses, there were no significant effects $[F(1,31)=$ $3.72, p<.07$, for effect of successive tests; all other $F \mathrm{~s}<1]$.

\section{Discussion}

Consistent with much of the literature, when bizarre and common items were presented in pure lists and re-

Table 2

Experiment 1: Net Recall, Item Gains, and Item Losses for the Combined Retrieval Condition

\begin{tabular}{|c|c|c|c|c|}
\hline \multirow[b]{3}{*}{ Dependent Measure } & \multicolumn{4}{|c|}{ Material } \\
\hline & \multicolumn{2}{|c|}{ Bizarre } & \multicolumn{2}{|c|}{ Common } \\
\hline & $M$ & $\overline{S E}$ & $M$ & $\overline{S E}$ \\
\hline \multicolumn{5}{|l|}{ Net Recall } \\
\hline Test 1 & .47 & .04 & .31 & .04 \\
\hline Test 2 & .49 & .04 & .37 & .04 \\
\hline Test 3 & .53 & .04 & .38 & .04 \\
\hline \multicolumn{5}{|l|}{ Item Gains } \\
\hline Test 2 & .84 & .22 & 1.44 & .27 \\
\hline Test 3 & .72 & .26 & .50 & .16 \\
\hline \multicolumn{5}{|l|}{ Item Losses } \\
\hline Test 2 & .34 & .12 & .38 & .16 \\
\hline Test 3 & .12 & .10 & .22 & .12 \\
\hline
\end{tabular}

Note-Net recall is proportion recall. Item gains and losses are number of items. called as pure lists, there was no significant advantage in free recall for nouns presented in bizarre sentences. Another way to gauge the advantage of bizarre sentences in this retrieval group is to note that the effect size was small (Cohen, 1977, pp. 413-414). In seven other experiments using similar materials (McDaniel \& Einstein, 1986; McDaniel et al., 1995), all of the effect sizes except one (McDaniel et al., 1995, Experiment $1, \eta^{2}=.07$ ) were medium or large (all with mixed lists). Thus, differential encoding of bizarre and common sentences was modest, if present, and certainly not extensive enough to mediate the robust bizarreness effects typically reported in free recall. Consistent with this conclusion, when successive recall tests were examined in the mixed-retrieval condition, there was no benefit of bizarreness for item gains in recall. If bizarre items enjoyed more extensive encoding, then amplified item gains would have been expected for those items (see Burns, 1993; Klein et al., 1989; McDaniel et al., 1998). The critical new result is that when bizarre and common items were studied separately in pure lists, but retrieved in the mixed context so that the retrieval set included both bizarre and common items, a significant and robust bizarreness effect emerged (the effect size was reflective of an effect midway between a medium- and large-size effect; Cohen, 1977).

These findings converge on the theoretically important conclusion that the significant bizarreness effect obtained here was primarily a function of processes operating at retrieval. Only when the retrieval context contrasted bizarre items with common items did bizarre items show a significant advantage in recall. Furthermore, the advantage was not at the expense of common item recall $(M=.31$ common items in both the combined retrieval set and the separate retrieval set), but was instead completely carried by an increase in bizarre item recall in the mixedretrieval context. This pattern is consistent with the idea that distinctiveness effects in recall, at least as manifested with bizarre materials, emerge because the features of unusual items are distinctive relative to features of other items in the retrieval set (Knoedler et al., 1999; McDaniel et al., 2000; McDaniel et al., 1995).

These results, however, do not necessarily imply that bizarreness effects are driven entirely by retrieval distinctiveness. The absence of a significant interaction between the bizarreness effect and retrieval group leaves open the possibility that differential encoding plays a significant role in mediating the recall advantage of bizarre sentences. If so, then it should be possible to augment encoding effects (increase the magnitude of the bizarreness effect). Experiment 2 tests this possibility.

\section{EXPERIMENT 2}

In this experiment, bizarre and common sentences were always presented in the same list during encoding. Robust differential encoding of bizarre and common items might be assumed to obtain only when bizarre and common items are intermixed in the same study list. That is, 
only when bizarre items are distinctive within the encoding context should bizarre items receive the additional processing or attention presumed to underlie the bizarreness effect (from the perspective of an encoding view; see Worthen et al., 1998). To facilitate the retrieval manipulations described next, the mixed list was constructed so that the first half of the list was composed of one type of sentence, and the second half of the list was composed of the other type of sentence. For recall, two retrieval conditions paralleling those in Experiment 1 were implemented. In one group, participants attempted recall of the entire list, so that bizarre and common sentences were in the same retrieval set. In another group, participants were instructed to recall the first half of the list (or second half of the list), and, having completed this recall task, were instructed to recall the second (or first) half of the list.

Previous research has demonstrated that mixed lists of bizarre and common sentences arranged in blocked fashion, as in the present experiment, and of equivalent length as that used in the present experiment (six bizarre and six common sentences), produce robust bizarreness effects in free recall (Hirshman et al., 1989, $\eta^{2}=.21$ for Experiment 3; see also Experiment 4). Furthermore, these results have been interpreted as support for an encoding account of the recall advantage for bizarre sentences (see the contextual encoding account in the introduction). Accordingly, if encoding accounts have merit, then a significant bizarreness effect should emerge regardless of whether retrieval is tested in the typical fashion (recall of the entire list) or by list half.

Alternatively, by the retrieval view, a significant bizarreness effect should emerge only when common items are also present in the retrieval set (recall of the entire list). That is, the strong prediction from this view is that even with a mixed study list that contains both bizarre and common sentences, when the retrieval set is subsequently limited to one type of sentence (recall by list half, with each half representing only one type of sentence), bizarre items will show no significant recall advantage relative to common items. In addition, any effect in this separate retrieval condition should be similar to the small effect found for the parallel retrieval group in Experiment 1. That is, if retrieval distinctiveness is the prominent factor in the bizarreness effect, then mixed study per se would not be expected to augment the small and nonsignificant bizarreness advantage (found in Experiment 1).

\section{Method}

Participants and Design. The design was a $2 \times 2$ mixed factorial, varying sentence type (common, bizarre) within subjects and retrieval condition between subjects. Bizarre and common sentences were presented in the same list. Following Hirshman et al. (1989), each sentence type was blocked in one half of the list. At test, participants were instructed either to recall the list of sentences by halves or to recall the entire list of sentences.

The participants were 64 undergraduates enrolled in a psychology course at the University of New Mexico or at New Mexico State University, who participated either in partial fulfillment of a course requirement or for extra credit. There were 32 participants in each retrieval group.
Materials. The stimulus materials were identical to those used in Experiment 1. Half the participants in each group received six common sentences first followed by six bizarre sentences, and half of the participants received six bizarre sentences first followed by six common sentences. Sentences appeared in the same type font; the first six sentences were presented on green paper and the last six sentences were presented on purple paper. This was done to provide additional cues by which the half-list recall group could differentiate the two sets of items (first half; second half).

In the group tested for recall by halves, half of the participants recalled the nouns from the green paper (the first six sentences) first and the purple paper (the last six sentences) second, and half of the participants recalled the nouns from the purple paper (the last six sentences) first and the green paper (the first six sentences) second.

Procedure. The experiment lasted approximately $30 \mathrm{~min}$. Encoding instructions were the same as those used in Experiment 1. However, following practice on two common sentences, participants read, imaged, and rated one list of 12 sentences, rather than two lists of 6 sentences.

The participants were then given a 5-min math problem distractor task, followed by the memory test for the capitalized nouns from the sentences. Participants instructed to recall by halves were reminded that the first six sentences (the first half of the list) had been presented on green paper and the last six sentences (the second half of the list) had been presented on purple paper. The participants were given 2.5 min to write down as many of the 18 capitalized nouns as possible from one color of paper (either the first six or the last six sentences) and then given 2.5 min to write down as many of the 18 capitalized nouns as possible from the other color of paper (either the last six or the first six sentences). Participants instructed to recall the whole list were given 5 min to write down as many of the 36 capitalized nouns from the whole list as possible. All participants were told they could write the words down in any order.

\section{Results and Discussion}

Free recall. The proportion of nouns recalled as a function of retrieval group and sentence type is displayed in Table 3. As in Experiment 1, a $2 \times 2$ mixed ANOVA (sentence type as the within-subjects variable and retrieval condition [whole-list, half-list recall] as the betweensubjects variable) was conducted, followed by planned comparisons testing the bizarreness effect in each retrieval condition. The ANOVA showed that bizarre items were generally recalled better than common items $\left[F(1,62)=12.21, M S_{\mathrm{e}}=8.11, p<.01, \eta^{2}=.16\right]$, and that retrieval condition did not significantly affect total recall levels $[F(1,62)=1.16]$. The interaction between retrieval condition and sentence type was not significant $[F(1,62)=1.05]$. The planned comparisons indicated that the whole-list retrieval condition produced a significant bizarreness effect $(.13$ advantage on average) $[F(1,62)=$ $\left.10.18, M S_{\mathrm{e}}=8.61, p<.01, \eta^{2}=.14\right]$. In contrast, for the half-list retrieval condition, the advantage for bizarre sentences was modest (.08 advantage) and nonsignificant $\left[F(1,62)=3.04, M S_{\mathrm{e}}=8.61, p<.10, \eta^{2}=.05\right]$. This nonsignificant difference was identical regardless of whether bizarre items or common items were recalled first $[F(1,30)<1$ for the interaction].

The major finding parallels that reported for Experiment 1. Identical encoding conditions produced somewhat different patterns of recall for bizarre and common items depending on the retrieval context. When bizarre and common items were intermixed in the retrieval set, 
Table 3

Experiment 2: Free Recall and Input-Output Correspondence

\begin{tabular}{|c|c|c|c|c|c|c|}
\hline \multirow[b]{3}{*}{ Retrieval Condition } & \multicolumn{4}{|c|}{ Free Recall } & & \\
\hline & \multicolumn{2}{|c|}{ Bizarre } & \multicolumn{2}{|c|}{ Common } & \multicolumn{2}{|c|}{ I-O Correspondenc } \\
\hline & $M$ & $S E$ & $M$ & $S E$ & $M$ & $S E$ \\
\hline Whole list & .44 & .04 & .31 & .03 & .49 & .04 \\
\hline Half list & .38 & .03 & .30 & .03 & .46 & .05 \\
\hline
\end{tabular}

the standard significant free recall advantage for bizarre items emerged (an effect of medium size), an advantage consistent with that reported by Hirshman et al. (1989) with similar materials and list construction (bizarre and common items blocked). On the other hand, when the retrieval set segregated bizarre and common items, the advantage for bizarre items was not statistically significant and represented a small effect. To gain more power to reveal the effects of retrieval context on the magnitude of the bizarreness effect, we combined Experiments 1 and 2 in a 2 (sentence type) $\times 2$ (retrieval condition) mixed ANOVA. The interaction representing robust bizarreness effects in the intermixed condition relative to the separate retrieval condition approached the criterion for statistical significance $\left[F(1,126)=3.46, M S_{\mathrm{e}}=8.57, p<\right.$ $.07]$. These patterns are not completely consistent with encoding views of bizarreness effects in recall.

A more complex account of Worthen et al. (1998) assumes that the encoding benefit for bizarre items fluctuates as a function of the proportion of bizarre items preceding any particular bizarre item (with greater encoding when the preceding context contains a lower proportion of bizarre items). Applied to the present experiment, this encoding view would anticipate that the bizarreness effect might be significantly more robust when the first half of the list was composed of common items (with bizarre items following) than when the first half of the list was composed of bizarre items. To test this idea, we conducted a $2 \times 2 \times 2$ mixed ANOVA (with sentence type and retrieval condition as variables) that included the counterbalancing variable of sentence order (bizarrecommon, common-bizarre). The bizarre item advantage was slightly but not significantly reduced for the bizarrecommon sentence order (.09 advantage) relative to the reverse order (.11 advantage) $(F<1$ for the interaction). Furthermore, both orders produced a significant bizarreness advantage, with effect sizes close to a medium-size effect $[\mathrm{F}(1,60) 55.24$, MSe 5 8.77, h2 5.08 , and $\mathrm{F}(1,60) 56.95$, $M S_{\mathrm{e}}=8.77, \eta^{2}=.10$, respectively].

Thus, the results converge on the view that bizarre items gain an advantage in recall by virtue of their distinctiveness relative to other items in the retrieval set (see Hunt \& McDaniel, 1993). We amplify on this idea in the General Discussion.

Input-output correspondence. Another possible interpretation for why the bizarreness effect was not statistically significant in the half-list retrieval condition must be considered. Requiring recall of the first/second half of the list may have encouraged participants to rely more extensively on order information, perhaps for example to help limit recall to the instructed half of the list. If so, then an encoding advantage of bizarre items (i.e., additional elaboration or item specific processing) could be negated because the additionally encoded information associated with the bizarre items would not necessarily be useful with an order retrieval strategy (e.g., see McDaniel et al., 2000).

To evaluate this possibility, for each of the experimental groups, we computed Asch-Ebenholtz (Asch \& Ebenholtz, 1962) scores to assess the correspondence of the output order during recall with the original input order. Following McDaniel et al. (2000), the first word recalled from each sentence was used to determine a particular sentence's output order. That is, if other words were recalled from the same sentence, they were ignored in computing the Asch-Ebenholtz score. For the half-list recall group, an output order score was computed for each of the two recall protocols (one for each half) and averaged to provide an indication of the degree to which those participants used an order strategy in general. For 5 participants in this group, an output-order score could not be computed for one of the half-list recalls (because for instance only items for one sentence were recalled), and in those cases the output order score from one halflist recall was used. One participant in the whole-list retrieval condition recalled items from just one sentence; consequently, an output order score could not be computed for that participant.

Table 3 shows the average scores. Scores of .50 indicate chance correspondence and scores of 1.00 indicate perfect correspondence. As can be seen, the scores were just below .50, indicating no use of serial order in guiding recall regardless of group. A one-factor ANOVA on these data revealed no significant differences in the use of order information at recall $(F<1)$. Thus, there is no evidence that the half-list recall procedure stimulated either significant reliance on order information or differential reliance on order information relative to the whole-list recall procedure, thereby ruling out an order-information retrieval account for the absence of a bizarreness effect in the half-list recall group (see McDaniel et al., 2000).

\section{GENERAL DISCUSSION}

This study is the first of which we are aware that has independently manipulated the encoding set of bizarre and common sentences (pure or mixed lists) and the retrieval 
set in free recall (separate or combined). The implementation of this paradigm is centrally important for the following reason. The memory literature is replete with experimental demonstrations that salient, unusual, or atypical items of a list are remembered better than less salient, usual, or typical items from the same list (for reviews, see DeLosh \& McDaniel, 1996; McDaniel et al., 1995; Schmidt, 1991; Waddill \& McDaniel, 1998), whereas the same unusual items presented in pure lists do not enjoy a significant recall advantage relative to usual items. Perhaps because the list constitution is explicitly manipulated for study purposes, and because the psychological phenomenon of salience in mixed lists is judged by learners to be mnemonically potent (see Dunlosky, Hunt, \& Clark, 2000; see also Kroll, Schepeler, \& Angin, 1986), the idea that this "distinctiveness effect" is mediated by the encoding processes has been widely favored. Yet, the encoding and retrieval contexts are inextricably bound in the experimental literature, thereby creating significant challenges in revealing the contributions of encoding versus retrieval processes.

The present results were consistent in this regard, with the combined patterns of Experiments 1 and 2 reflecting a clear and robust influence of retrieval and a marginal, more modest encoding influence. When the retrieval set consisted of both bizarre and common items as potential targets, bizarre items were significantly better recalled than common items, regardless of whether bizarre and common items were encoded in pure or mixed lists. The recall advantage for bizarre items was rendered nonsignificant when the retrieval context limited potential targets to one type of item, again regardless of the original encoding context.

\section{Implications for Accounts of Bizarreness Effects}

The present results suggest that a host of encoding accounts do not sufficiently capture the bizarreness effect (e.g., Hirshman et al., 1989; Merry, 1980; Wollen \& Cox, 1981; Wollen \& Margres, 1987). In their simplest instantiation, these accounts carry the theme that bizarre items are better encoded and thus should be better recalled. These accounts are inconsistent with the present findings that across identical encoding conditions, significant positive effects of bizarreness were not consistently obtained in free recall (but instead depended on the retrieval conditions), as well as by many other reports that bizarreness effects are not obtained in pure-list designs (see Einstein \& McDaniel, 1987, for a review; also McDaniel et al., 1995).

More complex variants of these encoding accounts have been formulated in light of the observation that bizarreness effects are generally limited to mixed lists. One idea is that augmented encoding for bizarre items is engaged only when bizarre and common items are mixed at study, thereby producing the typically robust bizarreness advantage in mixed lists (e.g., bizarre items "grabbing" differential attention when presented with common items or benefiting from more dramatic expectation violation in the presence of common items; e.g., see Worthen et al., 1998). Countering this idea, a mixed encoding procedure produced only a small and nonsignificant bizarreness effect when the recall context required separate recall of bizarre and common items (Experiment 2). Moreover, the magnitude of this nominal advantage was virtually identical to that when encoding was not mixed (and recall was separate; Experiment 1). The mixed presentation in Experiment 2 was patterned after a paradigm that has produced significant and consistently robust bizarreness effects (using 20 participants in a group), with an encoding account formulated to explain those effects (Hirshman et al., 1989, Experiments 3 and 4). The absence of a significant bizarreness effect with these mixed lists in the separate recall group (with 32 participants in the group) directly counters a pure encoding account.

A modification to this idea that might be offered as a post hoc account of the absence of significant bizarreness effects with mixed lists and half-list recall (Experiment 2) is that mixed lists stimulate differential encoding that is necessary but not sufficient to produce the effect - the retrieval context must also reinstate the mixed encoding context for the differential encoding to be effective. This view that mixed lists stimulate necessary differential encoding for bizarre items is not supported by Experiment 1. In Experiment 1, a significant bizarreness effect was obtained without the presence of mixed lists at encoding, when recall of both bizarre and common items were intermixed during retrieval. This pattern demonstrates that the bizarreness effect is not necessarily a function of a complex interlocking of intermixing at both encoding and retrieval.

Rather, the present study has shown that the bizarreness effect is contingent on the intermixing of bizarre and common items at retrieval. The small and nonsignificant advantage of bizarre items when there is no intermixing at retrieval may be consistent with the idea that both encoding and retrieval processes are involved in the bizarreness effect (e.g., McDaniel \& Geraci, in press; Worthen, in press). Our findings, however, provide support for the view that bizarreness effects are mediated primarily by processes emerging at retrieval (see also Riefer \& Rouder, 1992). Converging with this conclusion is that recognition tests for target items, tests that presumably attenuate retrieval demands (Hogan \& Kintsch, 1971), do not reveal a bizarreness effect (Emmerich \& Ackerman, 1979; McDaniel \& Einstein, 1986, Experiment 4).

Two views have been proposed concerning the nature of the retrieval dynamics that mediate the bizarreness effect in free recall. Worthen (in press) proposed that learners adopt a more liberal response criterion for bizarre than for common items during retrieval. This account does not clearly explain the present pattern, in which intermixing of bizarre and common sentences in the retrieval set was necessary for significant bizarreness effects. We suggest that the intermixing in the retrieval set allows bizarre items to become functionally distinct (see McDaniel et al., 2000; McDaniel et al., 1995). 


\section{The Role of Distinctiveness at Retrieval}

There are several ideas about how distinctiveness in the retrieval context might enhance recall. One is that distinctiveness may serve a discriminative function whereby the target item is better discriminated or identified as a target among possible candidates that emerge at retrieval (Hunt \& McDaniel, 1993; Knoedler et al., 1999). Another idea is that in a retrieval set of possible common and bizarre items, the unusual nature of the bizarre items (relative to prior experience that determines which information is unusual) provides a diagnostic cue that guides access or reconstruction of bizarre items (see Hunt \& Lamb, 2001; Waddill \& McDaniel, 1998). In a pure list of bizarre items, such a cue cannot serve a diagnostic function for access of particular items, and thus other dimensions determine recall (e.g., Knoedler et al., 1999; McDaniel et al., 2000). Recent models have formalized the just-mentioned idea as a relative match of a particular cue to a target item compared with that cue's match to all possible targets (see the SIMPLE model, Brown, Neath, \& Chater, 2002; and the feature model, Nairne, 1990; Neath, 2000). The larger the ratio, the more likely recall. Cues relating to the unusual nature of bizarre items would produce a greater relative match to bizarre items in mixed than in pure lists, thereby conferring an advantage to bizarre items in mixed lists.

The retrieval theories sketched above are consistent with the present finding that bizarre item recall was augmented in the group in which bizarre and common items were recalled together relative to the group in which only bizarre items were recalled. That is, in both Experiments 1 and 2, the bizarreness effect in the mixed-recall conditions was not a consequence of reduced recall of common items relative to the separate-recall condition. This pattern disfavors the interpretation that the bizarreness effect in the mixed-retrieval contexts was a combination of more strongly encoded bizarre items and favored output of those stronger items during initial recall (when bizarre and common items were recalled together). The idea here is that initial output of the well-encoded bizarre items in mixed-retrieval contexts would create output interference for more weakly encoded common items (see Roediger \& Schmidt, 1980). ${ }^{3}$ If so, then recall of common items in the mixed-retrieval contexts should have been reduced relative to the unmixed-retrieval contexts.

More generally, these theoretical ideas, along with the present empirical findings, may suggest that a theory of distinctiveness effects in recall need not invoke encoding dynamics, as some current theories do (see Schmidt, 1991; McDaniel \& Geraci, in press). Hunt and Lamb (2001) have converged on a similar conclusion in their investigations of salience effects in the isolation paradigm. It may thus be fruitful to consider a wide range of so-called distinctiveness effects, effects in which some items become salient by virtue of mixing those items at study with more typical items, from the perspective of the retrieval view of bizarreness effects supported herein.

\section{REFERENCES}

Asch, S. E., \& Ebenholtz, S. M. (1962). The process of free recall: Evidence for non-associative factors in acquisition and retention. Journal of Psychology, 54, 3-31.

Brown, G. D. A., Neath, I., \& Chater, N. (2002). A ratio model of scale-invariant memory and identification. Manuscript submitted for publication.

BuRNS, D. J. (1993). Item gains and losses during hypermnesic recall: Implications for the item-specific-Relational information distinction. Journal of Experimental Psychology: Learning, Memory, \& Cognition, 19, 163-173.

Burns, D. J., \& GolD, D. E. (1999). An analysis of item gains and losses in retroactive interference. Journal of Experimental Psychology: Learning, Memory, \& Cognition, 25, 978-985.

COHEN, J. (1977). Statistical power analysis for the behavioral sciences (rev. ed.). New York: Academic Press.

Cox, S. D., \& Wollen, K. A. (1981). Bizarreness and recall. Bulletin of the Psychonomic Society, 18, 244-245.

DeLosh, E. L., \& McDaniel, M. A. (1996). The role of order information in free recall: Application to the word-frequency effect. Journal of Experimental Psychology: Learning, Memory, \& Cognition, 22, 1136-1146.

DUNLOSKY, J., HUNT, R. R., \& CLARK, E. (2000). Is perceptual salience needed in explanations of the isolation effect? Journal of Experimental Psychology: Learning, Memory, \& Cognition, 26, 649-657.

Einstein, G. O., \& MCDANiel, M. A. (1987). Distinctiveness and mnemonic benefits of bizarre imagery. In M. A. McDaniel \& M. Pressley (Eds.), Imagery and related mnemonic processes: Theories, individual differences, and applications (pp. 78-102). New York: Springer-Verlag.

Einstein, G. O., MCDAniel, M. A., \& LACKey, S. (1989). Bizarre imagery, interference, and distinctiveness. Journal of Experimental Psychology: Learning, Memory, \& Cognition, 15, 137-146.

EMMERICH, H. J., \& ACKERMAN, B. P. (1979). A test of bizarre interaction as a factor in children's memory. Journal of Genetic Psychology, 134, 225-232.

Hauck, P. D., Walsh, C. C., \& Kroll, N. E. A. (1976). Visual imagery mnemonics: Common vs. bizarre mental images. Bulletin of the Psychonomic Society, 7, 160-162.

Hirshman, E. L., \& BJorK, R. A. (1988). The generation effect: Support for a two-factor theory. Journal of Experimental Psychology: Learning, Memory, \& Cognition, 14, 484-494.

Hirshman, E. L., Whelley, M. M., \& PALIJ, M. (1989). An investigation of paradoxical memory effects. Journal of Memory \& Language, 28, 594-609.

Hogan, R. M., \& KinTsCH, W. (1971). Differential effects of study and test trials on long-term recognition and recall. Journal of Verbal Learning \& Verbal Behavior, 10, 562-567.

HunT, R. R. (1995). The subtlety of distinctiveness: What von Restorff really did. Psychological Bulletin \& Review, 2, 105-112.

Hunt, R. R., \& Elliott, J. M. (1980). The role of nonsemantic information in memory: Orthographic distinctiveness effects on retention. Journal of Experimental Psychology: General, 109, 49-74.

HuNT, R. R., \& LAMB, C. A. (2001). What causes the isolation effect? Journal of Experimental Psychology: Learning, Memory, \& Cognition, 27, 1359-1366.

HUNT, R. R., \& MCDANIEL, M. A. (1993). The enigma of organization and distinctiveness. Journal of Memory \& Language, 32, 421-445.

Jenkins, W. O., \& Postman, L. (1948). Isolation and the spread of effect in serial learning. American Journal of Psychology, 61, 214-221.

Klein, S. B., Loftus, J., Kinlstrom, J. F., \& Aseron, R. (1989). Effects of item-specific and relational information on hypermnesic recall. Journal of Experimental Psychology: Learning, Memory, \& Cognition, 15, 1192-1197.

KNOEDLER, A. J., Hellwig, K. A., \& NeATH, I. (1999). The shift from recency to primacy with increasing delay. Journal of Experimental Psychology: Learning, Memory, \& Cognition, 25, 474-487.

Kroll, N. E. A., Schepeler, E. M., \& ANGIN, K. T. (1986). Bizarre imagery: The misremembered mnemonic. Journal of Experimental Psychology: Learning, Memory, \& Cognition, 12, 42-54. 
McDaniel, M. A., DeLosh, E. L., \& Merritt, P. S. (2000). Order information and retrieval distinctiveness: Recall of common versus bizarre material. Journal of Experimental Psychology: Learning, Memory, \& Cognition, 26, 1045-1056.

MCDANIEL, M. A., \& EINSTEIN, G. O. (1986). Bizarre imagery as an effective memory aid: The importance of distinctiveness. Journal of Experimental Psychology: Learning, Memory, \& Cognition, 12, 5465.

McDaniel, M. A., Einstein, G. O., Delosh, E. L., May, C. P., \& BRADY, P. (1995). The bizarreness effect: It's not surprising, it's complex. Journal of Experimental Psychology: Learning, Memory, \& Cognition, 21, 422-435.

MCDANIEL, M. A., \& GERACI, L. (in press). Encoding and retrieval processes in distinctiveness effects: Toward an integrative framework. In R. R. Hunt \& J. B. Worthen (Eds.), Distinctiveness and memory. New York: Oxford University Press.

McDaniel, M. A., Moore, B., \& Whitman, H. (1998). Dynamic changes in hypermnesia across early and late tests: A relational/item-specific account. Journal of Experimental Psychology: Learning, Memory, \& Cognition, 24, 173-185.

MERRY, R. (1980). Image bizarreness in incidental learning. Psychological Reports, 46, 427-430.

Mulligan, N. W. (2000). Perceptual interference at encoding enhances item-specific encoding and disrupts relational encoding: Evidence from multiple recall tests. Memory \& Cognition, 28, 539-546.

Mulligan, N. W. (2001). Generation and hypermnesia. Journal of Experimental Psychology: Learning, Memory, \& Cognition, 27, 436450.

NaIRne, J. S. (1990). A feature model of immediate memory. Memory \& Cognition, 18, 251-269.

NEATH, I. (2000). Modeling the effects of irrelevant speech on memory. Psychonomic Bulletin \& Review, 7, 403-423.

RIEFER, D. M., \& RoudER, J. N. (1992). A multinomial modeling analysis of the mnemonic benefits of bizarre imagery. Memory \& Cognition, 20, 601-611.

RoEDIGER, H. L., III, \& SCHMIDT, S. R. (1980). Output interference in the recall of categorized and paired associate lists. Journal of Experimental Psychology: Human Learning \& Memory, 6, 91-105.

ScHMIDT, S. R. (1991). Can we have a distinctive theory of memory? Memory \& Cognition, 19, 523-542.

ScHMIDT, S. R. (1994). Effects of humor on sentence memory. Journal of Experimental Psychology: Learning, Memory, \& Cognition, 20, 953-967.

SENTER, R. J., \& Hoffman, R. R. (1976). Bizarreness as a nonessential variable in mnemonic imagery: A confirmation. Bulletin of the Psychonomic Society, 7, 163-164.

SlamecKa, N. J., \& Katsaiti, L. T. (1987). The generation effect as an artifact of selective displaced rehearsal. Journal of Memory \& Language, 26, 589-607.
WadDill, P. J., \& McDaniel, M. A. (1998). Distinctiveness effects in recall: Differential processing or privileged retrieval? Memory \& Cognition, 26, 108-120.

WATKIns, M. J., LeCompte, D. C., \& Kim, K. (2000). Role of study strategy in recall of mixed lists of common and rare words. Journal of Experimental Psychology: Learning, Memory, \& Cognition, 26, $239-245$.

WOLLEN, K. A., \& Cox, S. D. (1981). Sentence cuing and the effectiveness of bizarre imagery. Journal of Experimental Psychology: Human Learning \& Memory, 7, 386-392.

Wollen, K. A., \& Margres, M. G. (1987). Bizarreness and the imagery multiprocess model. In M. A. McDaniel \& M. Pressley (Eds.), Imagery and related mnemonic processes: Theories, individual differences, and applications (pp. 103-127). New York: Springer-Verlag.

Wollen, K. A., Weber, A., \& Lowry, D. H. (1972). Bizarreness versus interaction of mental images as determinants of learning. Cognitive Psychology, 3, 518-523.

WORTHEN, J. B. (in press). Resolution of discrepant memory strengths: An explanation of the effects of bizarreness on memory. In R. R. Hunt \& J. B. Worthen (Eds.), Distinctiveness and memory. New York: Oxford University Press.

Worthen, J. B., Marshall, P. H., \& Cox, K. B. (1998). List length and the bizarreness effect: Support for a hybrid explanation. Psychological Research, 61, 147-156.

WORTHEN, J. B., STARNS, J. J., \& Loveland, J. M. (in press). Influence of orienting task on memory for bizarre and common stimuli: Evidence against a surprise-based explanation. In S. P. Shohov (Ed.), Leading edge research in cognitive psychology. Hauppage, NY: Nova Science.

\section{NOTES}

1. By retrieval set, we mean the set of items that share the episodic information (e.g., spatial/temporal context) specified in the recall request. For present purposes, this episodic information relates to the list context, but we assume that episodic memory requests specify, at least implicitly, some episodic context that identifies a retrieval set (see Hunt \& McDaniel, 1993, for amplification).

2. For the separate retrieval group in Experiment 1 and the half-list retrieval group in Experiment 2, we scored recall as correct regardless of whether the items were recalled with the original list (Experiment 1) or original half (Experiment 2). The present issues focused on item recall, and accordingly we did not want to embed source errors in our item recall scores.

3. We thank Cathy McEvoy for pointing out this possible interpretation.

(Manuscript received April 2, 2003; revision accepted for publication May 27, 2004.) 